\title{
THERMAL EFFECTS DURING CO2 LEAKAGE FROM A GEOLOGIC STORAGE RESERVOIR
}

\author{
Karsten Pruess \\ Earth Sciences Division, Lawrence Berkeley National Laboratory, Berkeley, CA 94720
}

\begin{abstract}
Leakage of $\mathrm{CO}_{2}$ from a geologic storage reservoir along an idealized fault zone has been simulated, including transitions between supercritical, liquid, and gaseous $\mathrm{CO}_{2}$. We find strong non-isothermal effects and nonmonotonic leakage behavior, due to an interplay between multiphase flow and heat transfer effects.
\end{abstract}

\section{Introduction}

The amounts of $\mathrm{CO}_{2}$ generated by fossil-fueled power plants are enormous, approximately 30,000 tonnes per day (10 million tonnes per year) for a coal-fired plant with 1,000 MW electric output [1]. Disposal of this $\mathrm{CO}_{2}$ in saline aquifers would generate plumes that over a typical lifetime of a power plant of 30-50 years would extend over a large area of $100 \mathrm{~km}^{2}$ or more [2]. This would make it all but inevitable that caprock weaknesses such as fault or fracture zones will be encountered that provide pathways for $\mathrm{CO}_{2}$ leakage from the primary disposal reservoir.

The objective of our study is to gain a better understanding of the fluid flow and heat transfer processes that would accompany $\mathrm{CO}_{2}$ migration away from the primary storage reservoir, towards shallow depths and ultimately to the land surface. We are especially interested in exploring self-enhancing and self-limiting leakage mechanisms.

\section{Conceptual Model}

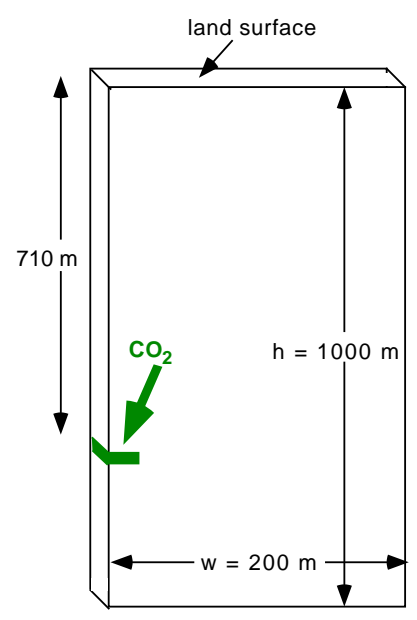

Figure 1. Idealized vertical fracture zone for modeling $\mathrm{CO}_{2}$ leakage.
In the present paper we model a potential leakage pathway as an idealized fracture zone or fault. The fracture zone shown in Fig. 1 is modeled as a 2-D porous medium with uniform permeability and porosity that is sandwiched between impermeable walls. Initial conditions are prepared by allowing a water-saturated system to run to steady state corresponding to land surface conditions of $\mathrm{T}_{1 \mathrm{~s}}=15{ }^{\circ} \mathrm{C}, \mathrm{P}_{1 \mathrm{~s}}=1.013$ bar, and a geothermal gradient of $30{ }^{\circ} \mathrm{C} / \mathrm{km}$ (see Fig. 2a). Leakage is initiated by applying $\mathrm{CO}_{2}$ at an overpressure of 9.5 bar over a width of $6 \mathrm{~m}$ at a depth of $710 \mathrm{~m}$ at the left hand side of the fracture zone. Boundary conditions at the top are maintained unchanged throughout the simulation. Lateral boundaries are "no flow." The walls bounding the fracture zone are assumed impervious to fluids but are participating in conductive heat exchange with the fluids in the fracture. Our focus is on heat transfer effects on $\mathrm{CO}_{2}$ migration and multiphase processes that involve phase change between liquid-like and gas-like $\mathrm{CO}_{2}$.

The thermodynamic issues relevant to upflow of $\mathrm{CO}_{2}$ from a deep storage reservoir are illustrated in Fig. 2a, which shows hydrostatic pressure profiles calculated for two average land surface temperatures of $\mathrm{T}_{1 \mathrm{~s}}=5{ }^{\circ} \mathrm{C}$ and 15 ${ }^{\circ} \mathrm{C}$, respectively, for a temperature gradient of $30{ }^{\circ} \mathrm{C}$ per $\mathrm{km}$ that is typical for continental crust. These profiles pass in the vicinity of the critical point, indicating a considerable expansion of $\mathrm{CO}_{2}$ migrating upward (Fig. 2b).

*Tel. (510) 486-6732, Fax. (510) 486-5686, Email: K_Pruess@lbl.gov 


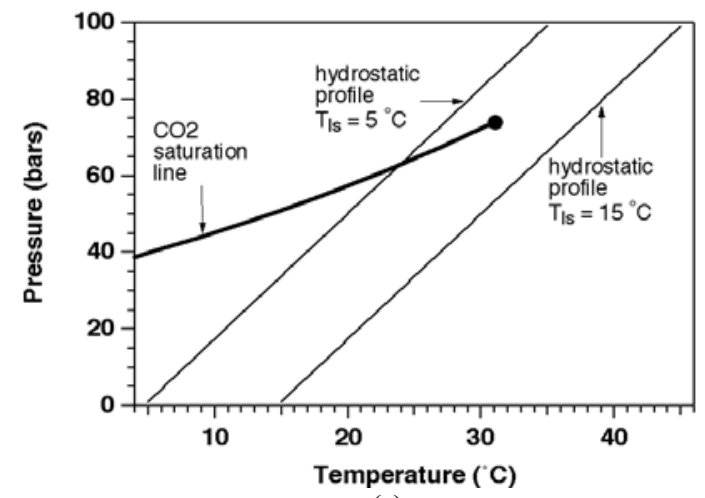

(a)

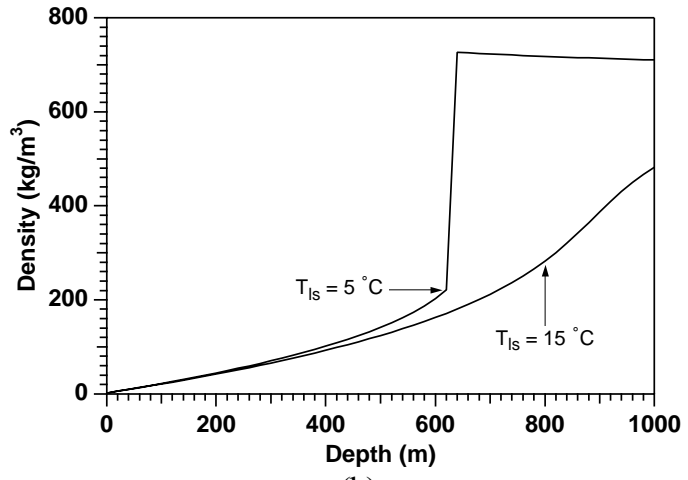

(b)

Figure 2. (a) $\mathrm{CO}_{2}$ saturation line and hydrostatic pressure-temperature profiles for typical continental crust; (b) density of $\mathrm{CO}_{2}$ vs. depth for the two hydrostatic profiles shown in Fig. 2a.

\section{Results}

All simulations were performed with our general-purpose code TOUGH2 [3] using a newly developed fluid property module that treats all seven possible phase combinations in the three-phase system aqueous - liquid $\mathrm{CO}_{2}$ gaseous $\mathrm{CO}_{2}$. Results are shown in Figs. 3-5. The dynamical behavior of the system is quite complex, the most striking feature being quasi-periodic variations in thermodynamic and other parameters, that arise from coupling between multiphase fluid flow and associated heat transfer processes that operate on different time scales.

The $\mathrm{CO}_{2}$ entering the fault zone partially dissolves in the aqueous phase, but most forms a separate supercritical phase that is immiscible with water. Due to buoyancy the $\mathrm{CO}_{2}$ rises whereupon it decompresses and cools, initiating conductive heat transfer from the wall rocks to the fluids flowing in the fault zone. After some time temperatures decrease to where thermodynamic conditions of $\mathrm{CO}_{2}$ reach the saturation line, forming a three-phase system aqueous - liquid $\mathrm{CO}_{2}$ - gaseous $\mathrm{CO}_{2}$. Upflow through the three-phase zone is impeded by interference between the phases, causing sideways diversion and lateral growth of the $\mathrm{CO}_{2}$ plume (Fig. 3). Diminishing $\mathrm{CO}_{2}$ fluxes towards the top of the three-phase zone slow the growth of this zone, and eventually allow conductive heat transfer towards this region from the wall rocks to "catch up" and boil away most of the liquid phase, shrinking the overall volume in which three-phase conditions are present. The entire cycle then repeats, giving rise to quasiperiodic excursions in total volume of the three-phase zone, with corresponding cyclic variations in flow rates, temperatures, and pressures (Fig. 4). In each successive cycle the three-phase zone reaches larger thickness and areal extent, and lower temperatures, as the heat inventory in the wall rocks is slowly being depleted.

Fig. 4a shows that $\mathrm{CO}_{2}$ flux at the land surface above the leakage point $(\mathrm{x}=2 \mathrm{~m})$ is out of phase with the variations in three-phase volume, reflecting increased flow impedance (mobility blockage) in this zone. $\mathrm{CO}_{2}$ flux at a point that is laterally offset $(\mathrm{x}=180 \mathrm{~m})$ is in-phase with three-phase volume at early times, because a thicker and areally more extensive three-phase zone above the leakage point diverts more $\mathrm{CO}_{2}$ sideways. At late time the threephase zone extends almost across the entire fault zone, and an increased three-phase volume reduces $\mathrm{CO}_{2}$ upflow rates everywhere. The laterally offset flux therefore is out of phase with three-phase volume at late time.

Maxima in three-phase volume correlate with minima in temperatures at $450 \mathrm{~m}$ depth, above the leakage point and near the top of the three-phase zone, at early times (Fig. 4b). This reflects local depletion of internal heat energy in the rock, and subsequent temperature recovery as the three-phase zone shrinks. The phase shift between threephase volume and temperature cycles changes over time as the three-phase zone thickens, and boiling becomes most intense at shallower depths.

The tendency of $\mathrm{CO}_{2}$ upflow to be self-limiting is entirely due to thermal effects. This can be demonstrated most directly by a simulation in which rock specific heat is set to a very large value, so that heat transfer limitations are removed and temperatures remain unchanged from their initial values. In this case we obtain no three-phase zone at all, and $\mathrm{CO}_{2}$ leakage rates increase monotonically with time (results not shown). 

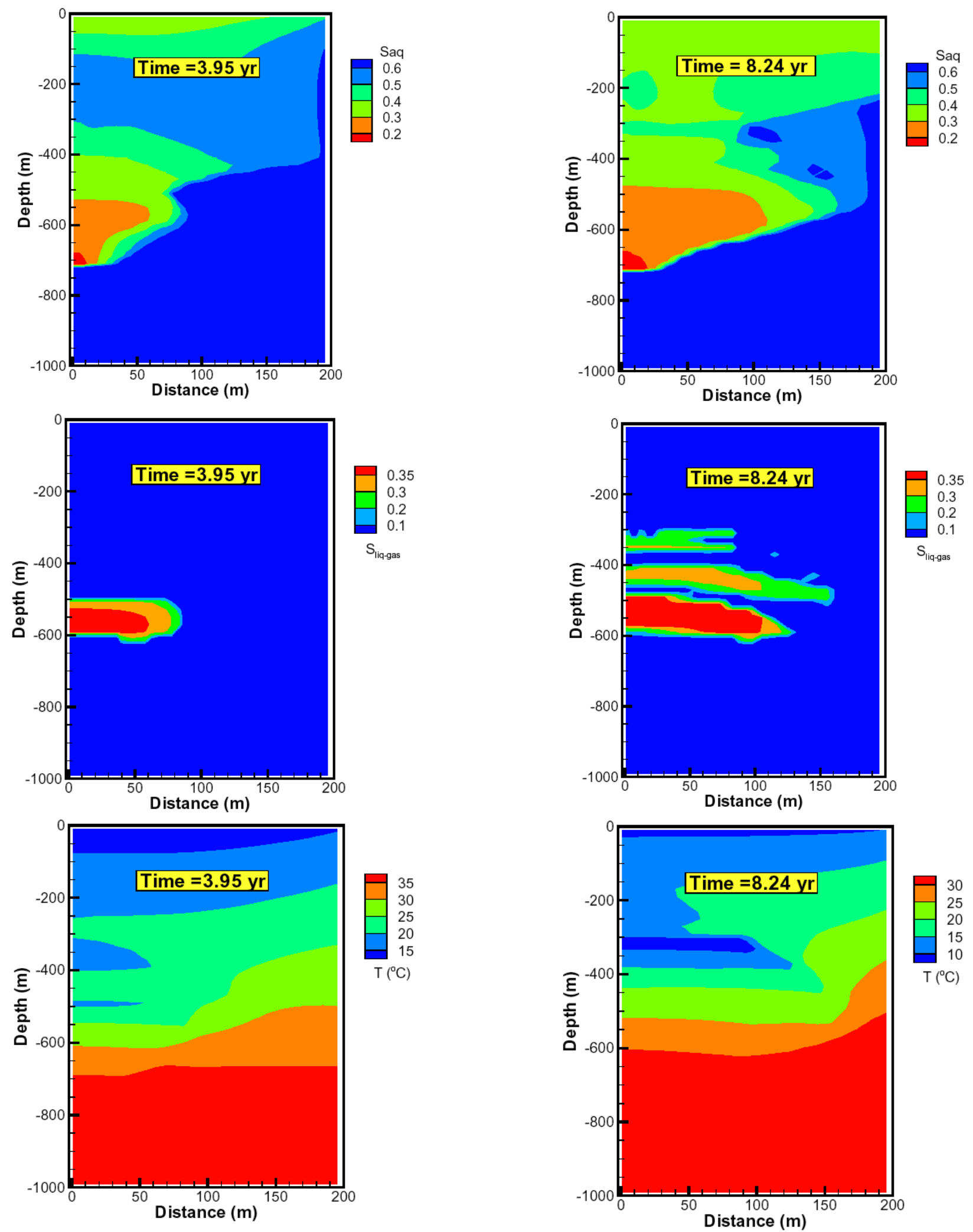

Figure 3. Snapshots of system evolution at two different times. The parameter Sliq-gas is defined as $\sqrt{S_{\text {liq }} \cdot S_{\text {gas }}}$, which is non-zero only for three-phase conditions. 


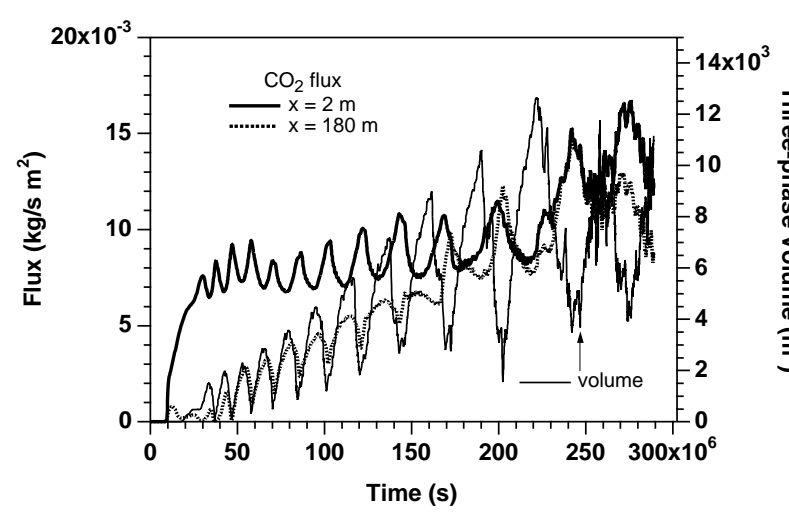

(a)

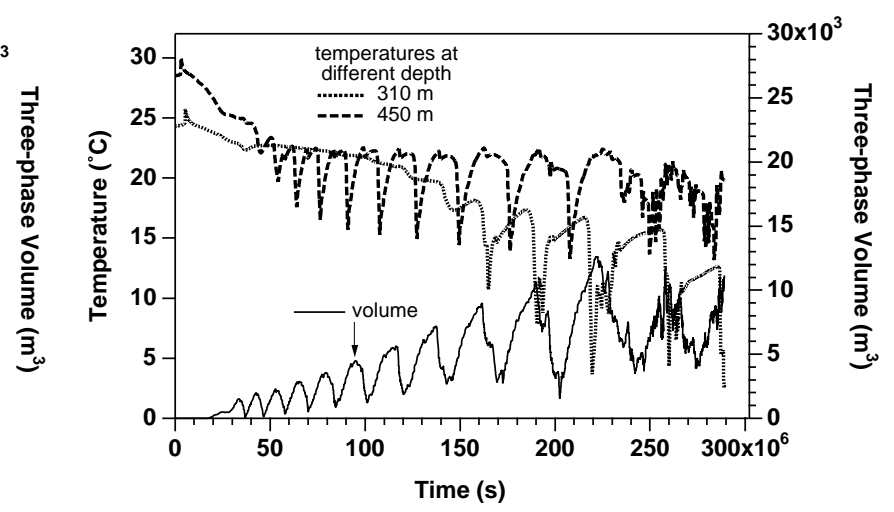

(b)

Figure 4. Temporal variation of total volume in three-phase conditions, compared with behavior of $\mathrm{CO}_{2}$ fluxes (a) and temperatures $(\mathrm{b})$ at selected locations.

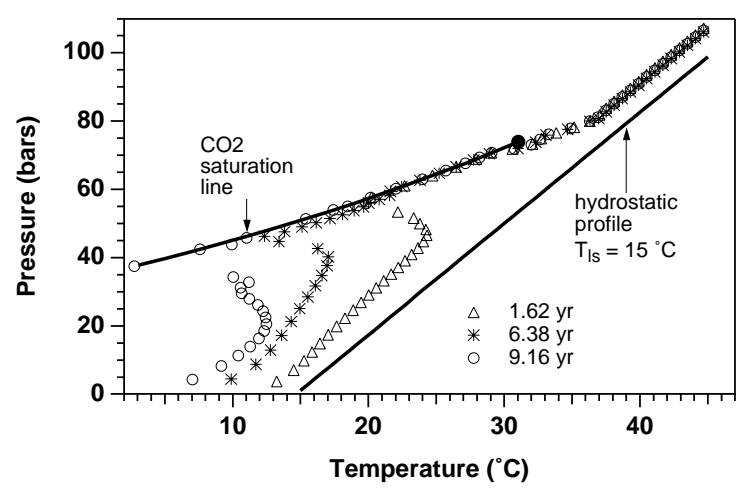

Figure 5. Pressure-temperature profiles in the leftmost column of grid blocks at different times.
Fig. 5 shows temperature and pressure conditions at different times in the leftmost column of grid blocks. The line labeled "hydrostatic profile" represents initial conditions prior to introduction of $\mathrm{CO}_{2}$. In the deeper portion of the profile we have single-phase aqueous conditions, and pressures show a constant increment of 9.5 bars, due to the applied $\mathrm{CO}_{2}$ pressure of 80 bars at $710 \mathrm{~m}$ depth, where hydrostatic pressure is 70.5 bars. Points with pressures less than 80 bars correspond to multiphase conditions with $\mathrm{CO}_{2}$. It is seen that thermodynamic conditions are drawn towards the critical point and subsequently track the saturation line, extending to lower temperatures and pressures at later times. The points with lower pressures below the saturation line correspond to two-phase conditions of aqueous - gaseous $\mathrm{CO}_{2}$ at shallower elevations, above the top of the three-phase zone.

\section{Concluding Remarks}

Numerical simulation of $\mathrm{CO}_{2}$ leakage along faults and fracture zones reveals a complex interplay of multiphase flow processes with strong non-isothermal effects. System behavior is dominated by cooling effects from $\mathrm{CO}_{2}$ decompression and boiling of liquid $\mathrm{CO}_{2}$ into gas. Heat transfer limitations cause cyclic, non-monotonic flow behavior and tend to limit $\mathrm{CO}_{2}$ flow rates at the land surface.

\section{Acknowledgement}

This work was supported by the Director, Office of Science, Office of Basic Energy Science of the U.S. Department of Energy under Contract No. DE-AC03-76SF00098.

\section{References}

1. Hitchon, B. (ed.). 1996. Aquifer Disposal of Carbon Dioxide, Geoscience Publishing, Ltd., Sherwood Park, Alberta, Canada.

2. Pruess, K., T. Xu, J. Apps and J. García. 2003. Numerical Modeling of Aquifer Disposal of $\mathrm{CO}_{2}$, Paper SPE83695, SPE Journal, pp. 49 - 60.

3. Pruess, K., C. Oldenburg and G. Moridis. 1999. TOUGH2 User's Guide, Version 2.0, Lawrence Berkeley National Laboratory Report LBNL-43134, Berkeley, CA, November. 